\title{
Optimizing Strategies of English Audio-Visual Classroom Teaching from the Perspective of Cultural Comparison
}

\author{
Zheng Pingfei \\ School of Foreign Languages, Tianhe College of Guangdong Polytechnic Normal University, \\ Guangzhou510000, China. \\ Springnazheng@163.com
}

Keywords: culture; English; Audio-Visual classroom Teaching; Cultural differences

\begin{abstract}
College English audio-visual classroom plays an important role in college English teaching. In the process of college English audio-visual teaching, cultural comparison teaching mode has become the norm. Through the practice of classroom teaching of college English audio-visual speaking, the practical and efficient teaching strategies of college English audio-visual speaking can make up for the deficiency in teaching practice. From the perspective of cultural comparison, the highly information-based society promotes the process of multimedia teaching. However, due to the differences in history, economic development and social formation among countries, there are similarities and differences in language forms and cultural connotations. It is necessary to integrate cultural differences in college English teaching. In the classroom teaching of English audio-visual speaking, through the exploration of the western thinking mode, to grasp the difference and to understand the difference, to better combine the Chinese and the western culture, to find out the internal relation of the Chinese and the western culture. Then the language expression ability and the thinking expression ability are improved gradually.
\end{abstract}

\section{Introduction}

With the increasingly close economic, political and cultural exchanges among countries in the world, countries are closely linked, and cross-culture also emerges. Cross-culture puts two or more different cultures in the same space, and cross-cultural understanding collides and blends in this common cultural practice environment, thus forming cultural facts. The emergence of culture also represents the emergence of differences. How to make students digest this cultural difference in college English teaching is the content to be studied in this paper, so as to provide some valuable reference for college English educators ${ }^{[1]}$.

Language is a tool used by human beings to spread knowledge and communicate with each other, and the study of foreign languages is not only to master the vocabulary, grammar, sentence structure and so on of the language itself ${ }^{[2]}$. Learners should focus on the use of language skills to understand and explore their representative social culture. College English audio-visual classroom is unique in college English teaching, which has great significance to the development and future of 
computer-assisted teaching and cultural comparison teaching ${ }^{[3]}$. We need to make full use of integrate cultural comparative discourse factors in the classroom, stand at the height of the leader, from the perspective of students, enrich the classroom content, arouse the enthusiasm of students to learn and participate in classroom practice, changing the dull atmosphere of listening to the answers in the traditional classroom provides a platform for teachers to reflect their self-worth in classroom teaching. As college teachers in the new era, only by constantly surpassing ourselves, studying the theory and exploring more reasonable, practical and efficient classroom teaching strategies can we optimize the classroom discourse mode. It needs to improve the language learners' comprehensive language use and processing ability, and truly achieve the teaching goals and tasks. This paper studies the optimization strategies of English audio-visual classroom teaching from the perspective of cultural comparison. Through the practice of college English audio-visual speaking classroom teaching, this paper explores practical and efficient teaching strategies of college English audio-visual speaking, which can make up for the deficiencies in teaching practice. In order to improve the teaching quality of college English, we should make use of various factors and teaching resources in cultural comparative teaching to integrate visual, listening and speaking into one body, so as to combine them organically, interact with each other and infiltrate each other to improve the teaching quality of audio-visual speaking in college English ${ }^{[4]}$.

\section{Comparison of Chinese and Western cultures and language differences}

The differences in values between the two cultures will lead to pragmatic failure in intercultural communication $^{[5]}$. The comparison between Chinese and Western cultures and linguistic differences are mainly manifested as follows:

\subsection{Abstract thinking and image thinking}

The traditional way of thinking in our country is to concretize things by inertia, and this kind of thinking has been continued up to now. We are used to express things with concrete impressions or sounds. But the West is different, their thinking tends to be abstract, good at reasoning, pay attention to the change of time and space. This will make China and the West in the use of sentences, there is a difference.

\subsection{Decentralized thinking and overall thinking}

China has always attached the most importance to the exploration of heaven and earth, which can be seen from the structure of Chinese, our language description is very pay attention to the integrity of the language. The West is not the same, because the analysis of things is the most important part, so the most critical part is the part that should be described. Therefore, the feature of fuzziness in Chinese is that the most important part of language integrity and comprehensiveness is that there should be no two sentences in one sentence, but fuzziness and brevity are emphasized in English, while logic is emphasized in English ${ }^{[6]}$.

\subsection{Object thinking and subject thinking}

Our country always stresses the unity of nature and man, and the sense of participation is very strong, which emphasizes the unity of subject and object all the time, so the active sentence structure is often used in the description. However, in western culture, the object and the subject are separated, and the object will be centered in the description of the object. Therefore, in western English, many sentence patterns are mainly passive. 


\section{Classroom teaching model of College English Audio-Visual speaking from the perspective of comparison}

Language and culture carry the past, present and future of a country. They are important symbols of a country and a nation. However, due to the differences in history, economic development and social formation among countries, It leads directly to the similarities and differences in language forms and cultural connotations. This leads to pragmatic failure in cross-cultural communication, which leads to the failure of cross-cultural communication. Therefore, it is necessary to integrate cultural differences in college English teaching. Through the exploration of the western way of thinking, the students find out the internal relation between Chinese and western culture, and then improve the language expression ability and the thinking expression ability gradually ${ }^{[7]}$.

Under the new situation of the development of higher education in China, the Ministry of Education has been advocating deepening the teaching reform, improving the teaching quality, encouraging college English teachers to use network and multimedia technology efficiently to complete the teaching and transmission of knowledge. From the perspective of cultural comparison, the highly information society promotes the process of multimedia teaching. Images, sounds and other symbols emerge in large numbers in teaching practice, and together with the traditional single language symbols become an indispensable way of information exchange in classroom teaching. Therefore, the academic community began to pay attention to these active social symbols, the focus of research once focused on how to use these symbols efficiently in teaching ${ }^{[8]}$. "Cultural comparison" refers to the various ways in which different symbolic patterns are included in a finished communication or communication activity, and that different symbolic resources are mobilized in a particular text to construct meaning. Traditionally, music, images and other visual symbols, which are considered non-verbal or paralanguage, are involved in the construction of meaning along with literal symbols in communication. The cultural comparative teaching model focuses on the cultivation of language learners' pluralistic ability, and advocates the use of pictures, images, limbs and activities to stimulate the sense organs of language learners, to make them feel the same feelings and to promote learning. In the practice of culture comparison teaching, learners perceive, understand, encode and store the received information, and the input information and knowledge obtained and stored provide protection for the unconscious and conscious language output at the same time. So as to form a benign language learning ${ }^{[9]}$.

\section{Restrictive factors of comparative classroom teaching of College English Audio-visual speaking culture}

Although the cultural comparative teaching model has been widely used in college English audio-visual courses due to the advantages mentioned above, there are still many restrictive factors in teaching practice.

First, the hardware facilities are complete, but the use effect is not good. Some teachers are not proficient in the operation of computers and the use of teaching software, and are unable to give full play to the role of multimedia language laboratories in teaching; some teachers are not enthusiastic enough and adhere to the traditional teaching mode. These factors restrict the healthy development of cultural comparative classroom teaching ${ }^{[10]}$.

Second, some teachers abuse multimedia in college English audio-visual teaching practice and lose their leading role in teaching. These teachers play the role of slide courseware projector, click the mouse, stare at the screen, the classroom is completely unorganized activity scene, students like cinema audience, helplessly looking at the flash picture, no interaction with the teacher. In such teaching, cultural comparative teaching, which seems to use many modern teaching methods, is no different from the traditional preaching and spoon-feeding teaching in essence. 
Third, some teachers have even violated the teaching plan and arrangement, playing movies, animation or music works that have nothing to do with the teaching content in the audio-visual classroom, and the teaching equipment invested by the school becomes the classroom entertainment facilities.

Fourth, some students are influenced by computer and mobile phone, their learning attitude is not correct and lack of enthusiasm, and they do not participate in classroom activities in the course of class, which affects the teachers' teaching passion and weakens the classroom teaching effect.

Teachers should fully take these disadvantages into account in audio-visual speaking classroom teaching and realize that multimedia technology is only a tool to assist teaching and cannot determine the teaching effect. Only when multimedia technology and teaching methods are integrated can they play a full role. At the same time, teachers should keep pace with the times, integrate cultural comparative discourse factors into college English audio-visual classroom, and change the traditional teaching method into a new interactive mode of knowledge input and output $^{[11]}$.

\section{Classroom Teaching Strategies of College English Audio-Visual speaking from the perspective of cultural differences}

As a new type of curriculum, college English audio-visual speaking classroom is different from traditional listening class in two aspects. First, rich content. Audio-visual teaching material integrates language, culture and social communication through video, audio and other interactive methods. The content includes classic soundtrack video clips, English songs, situational reproduction and so on. After audio-visual appreciation of the above content, there will be related oral practice. Students naturally switch from information input to output and use the expressions in audiovisual appreciation to practice oral English quickly and practically while the iron is hot. Second, diversified forms. In audiovisual class, students are stimulated by multi-senses when they input information, so it is easier to accept new information and knowledge, and to practice and imitate actively ${ }^{[12]}$.

Because of the differences in thinking patterns, Chinese and English have led to differences in language. If we continue to stand still, sooner or later we will be out of touch with the world, so if we want to use English better, we must first change our thinking ${ }^{[13]}$. The best way to learn English well is to master the differences and understand the differences and combine the Chinese and western cultures better.

\subsection{Strategies in classroom teaching}

First of all, because of the differences in thinking between China and the West, college English teachers can not only stay in the study of idioms, grammar and words, but also the penetration of custom to western culture. Teachers try to use the whole English classroom in classroom teaching, create a real language environment, through the completion of English and students' communication and evaluation, so that students can form a good habit of thinking in English. Second, English teachers should strive to recommend the original English works to students so that they can read them so that they can understand more about English and communicate with each other. The third is to solve the gap between western culture and Chinese culture, to find out the differences between Chinese and western cultures, to cultivate the students' English thinking mode, and to find out the correct form of English expression ${ }^{[14]}$. 


\subsection{Pay attention to the differences in language structure between Chinese and English}

The main purpose of learning English is to communicate smoothly with people through English. However, Chinese college students lack this kind of situation in learning English, so it is very difficult to make good use of English thinking to communicate. This requires the use of a large amount of English reading and listening to the accumulation of English. In this way, students not only learn more English knowledge, increase vocabulary, but also familiarize themselves with some ways of thinking and expressing English. If the differences between Chinese and western students in the curriculum cannot be fully integrated, teachers can find out the differences between English language structure and Chinese structure one by one, and compare the differences slowly. For example, in the address description, the order of expression in English is house, street, province and country, but in our country the opposite is true ${ }^{[15]}$. The teacher should choose the original sound film with pure pronunciation and prepare lessons carefully before class so as to play the leading role and effectively control the progress of the teaching link. The appropriate length is 5 minutes and 8 minutes. After viewing, the students can learn actively and participate in class by discussing in groups. Then, through the extraction and elaboration of the language content in the segment, the students are guided to learn deeply. Students with high English listening and speaking ability can organize impromptu speeches or debates in class to fully demonstrate the role of cultural comparative discourse theory in audio-visual teaching and the advantages of interactive teaching mode. Of course, teachers should remember the role of the guide, let students play their full ability, show the charm and charm of the language.

\subsection{Accumulation of cultural and social knowledge in English-speaking countries}

Understanding is the basis of communication. College English learners can understand the cultural connotations of English countries through reading foreign language publications, watching foreign movies, listening to English broadcasts and so on. On the basis of this, we combine and separate Chinese and English cultures to cultivate English learners' intercultural communicative competence. For example, the Chinese people's interpersonal relationships tend to be emotional and mixed, confusing personal and public relations, paying more attention to face, human feelings, paying attention to reciprocity, internal and external differences, which also has an invisible constraint on social behavior. Most Western countries, however, pay little attention to face and human relations, pay more attention to personnel, do business, pay more attention to reason and equal treatment. In cross-cultural communication, misunderstanding may occur if there is no good understanding of interpersonal relations, so it is necessary to have a wide range of understanding. In addition, teachers can organize students to "Guided Speaking". According to the teaching needs, the teacher displays the demonstration dialogue, the dialogue of the classic soundtrack film lines, or the speech, telling the students to pay attention to how to express the way of expression and the words required for the given topic. Students may be asked to imitate the content of the assigned material on the second or third pass. Students should integrate pronunciation, intonation, expression and action in imitation, and display video or listening content culturally. Then students can be arranged to do "Presentation". "Guided Speaking" can not only adjust the classroom atmosphere, but also help students to use input information timely output. Teachers should sum up and analyze students' performance and praise them so as to improve students' enthusiasm.

\section{Conclusions}

College English audio-visual classroom is unique in college English teaching, which is of great significance to the development and future of computer-assisted teaching and cultural comparison 
teaching. Make full use of, integrate cultural comparative discourse factors in the classroom, stand at the height of the leader, from the perspective of students, enrich the classroom content, arouse the enthusiasm of students to learn and participate in classroom practice, Changing the dull atmosphere of listening to the answers in the traditional classroom provides a platform for teachers to reflect their self-worth in classroom teaching. In order to improve intercultural communicative competence, it is necessary for English learners to master accurate learning and communication methods and to accumulate the cultural characteristics, language habits and social customs of English and native language countries. English learners should not only master certain methods of cultivating intercultural communicative competence, but also familiarize themselves with the language environment other than their mother tongue, deeply understand their national culture, and reduce pragmatic failures in intercultural communication. In order to optimize the classroom discourse mode, we can improve the classroom teaching of college English audio-visual speaking from the perspective of cultural comparison and explore more reasonable, practical and efficient teaching strategies in the classroom. Improve language learners' comprehensive language use and processing ability.

\section{References}

[1] Zhang Yuzhen. Research on English learning strategies under the multimedia network environment [J]. Chinese Language Journal (foreign language education and teaching), 2014, 09: 92-93,95.

[2] Liu Qizhi, Gan Guosheng. Strategies for College English Vocabulary Learning in Multimedia and Network environments[J]. Modern Educational Technology, 2009(02): 71-73.

[3] Feng Lixin. A study on the effectiveness of College English Autonomous Learning Strategies in Network Multimedia Environment[J]. Modern educational technology, 2013, 01: 59-63.

[4] Xie S L,Liu Y,Yang J M,et al.Time-Frequency Approach to Underdetermined Blind Source Separation[J].IEEE Transactions on Neural Networks and Learning Systems,2012,23(2):306-315.

[5] Wang N N,Chen G L.A Virus Spread Model Based on Cellular Automata in Weighted Scale-Free Networks [J].Advances in Intelligent Systems and Computing,2013,181: 1169-1175.

[6] Zhu Q Y,Yang X F,Yang L X, et al.Optimal control of computer virus under a delayed model [J].Applied Mathematics and Computation,2012,218(23): 11613-11619.

[7] Zhu Q Y,Yang X F, Ren J G.Modeling and analysis of the spread of computer virus [J].Communications in Nonlinear Science and Numerical Simulation,2012,17(12),5117-5124.

[8] Mahmoud E E. Complex complete synchronization of two nonidentical hyperchaotic complex nonlinear systems[J]. Mathematical Methods in the Applied Sciences, 2014, 37(3): 321-328.

[9] Palomares I, Martinez L, Herrera F. A consensus model to detect and manage non-cooperative behaviors in large scale group decision making[J]. IEEE Trans on Fuzzy System, 2014, 22(3): 516-530.

[10] Zhang H, Wang Z, Liu D A. Comprehensive review of stability analysis of continuous-time recurrent neural networks[J]. IEEE Trans on Neural Networks and Learning Systems, 2014, 25(7): 1229-1262.

[11] BOUDIA O R M, SENOUCI S M, FEHAM M, A novel secure aggregation scheme for wireless sensor networks using stateful public key cryptography [J]. Ad Hoc Networks, 2015, 32(C): 98-113.

[12] CHEN S, WANG G, JIA W. Cluster-group based trusted computing for mobile social networks using implicit social behavioral graph [J]. Future Generation Computer Systems, 2016,55: 391-400.

[13] ZHANG Q Y, WANG R C, SHA C, et al. Node correlation clustering algorithm for wireless multimedia sensor networks based on overlapped FoVs [J]. Journal of China Universities of Posts and Telecommunications, 2013, 20(5): 37-44.

[14] YE Q, ZHAO C, YE N. Least squares twin support vector machine classification via maximum one-class with-in class variance[J]. Optimization Methods and Software, 2012, 27(1):53-69.

[15] LIN T Y, SANTOSO H A, and WU K R. Global sensor deployment and local coverage- aware recovery schemes for smart environments[J]. IEEE Transactions on Mobile Computing, 2015, 14(7): 1382-1396. 